\title{
Apocrine Sweat Gland Ductal Adenoma with Sebaceous Differentiation in a Dog
}

\section{Masaki Michishita, Junki Yasui, Rei Nakahira, Hisashi Yoshimura, and Kimimasa Takahashi}

Department of Veterinary Pathology, Nippon Veterinary and Life Science University, 1-7-1 Musashino, Kyounan-cho, Tokyo 180-8602, Japan

Correspondence should be addressed to Masaki Michishita; michishita@nvlu.ac.jp

Received 12 November 2013; Accepted 28 November 2013

Academic Editors: N.-Y. Park and R. L. Santos

Copyright (C) 2013 Masaki Michishita et al. This is an open access article distributed under the Creative Commons Attribution License, which permits unrestricted use, distribution, and reproduction in any medium, provided the original work is properly cited.

A 7-year-old male, Border Collie, developed a firm mass, measuring approximately $1 \mathrm{~cm}$ in diameter, in the left buccal skin. Histologically, the mass was composed of ductal structures lined by bilayered luminal epithelial and basaloid tumor cells along with a few nests of sebaceous cells. Immunohistochemical staining revealed that the luminal epithelial tumor cells were positive for cytokeratin (CK, CAM5.2) and CK19 but not for CK14 or p63. In contrast, the basaloid tumor cells were positive for CK14, p63, and aSMA but not for CK19 or CAM5.2. CK8 expression was observed in both luminal epithelial and basaloid tumor cells. The tumor cells with sebaceous differentiation were positive for CK14 but not for the other markers. This is the first case of an apocrine sweat gland ductal adenoma with sebaceous differentiation occurring in the buccal skin of a dog.

\section{Introduction}

Apocrine sweat gland tumors are rather common in dogs and tend to occur on the head, neck, and limb. Approximately $70 \%$ of canine apocrine sweat gland tumors are benign in nature [1]. Benign tumors of the apocrine sweat gland are classified as apocrine adenomas, complex and mixed apocrine adenomas, or apocrine ductal adenomas [2]. Apocrine ductal adenomas in dogs are uncommon benign neoplasms and accounted for only $0.3 \%$ of canine skin tumors in a large survey [1]. In dogs, sebaceous differentiation has been described in five cases of mammary gland tumors [3-6]. However, to the authors' knowledge, a nonmammary-associated apocrine tumor with sebaceous differentiation in dog has not been previously reported.

\section{Case Report}

A 7-year-old male, Border Collie, developed a firm mass in the left buccal skin, which was surgically removed and submitted to the Department of Veterinary Pathology, Nippon Veterinary and Life Science University (Tokyo, Japan), for histopathological examination. Grossly, the mass was approximately $1 \mathrm{~cm}$ in diameter, and a cut surface of the mass appeared homogeneously greyish-white in color. A physical examination including complete blood count and a routine serum biochemical profile revealed no further abnormalities. Detailed radiographic and X-ray examinations did not reveal any mass suggestive of a tumor in the thoracic and abdominal cavities. No tumor recurrence or metastasis was noted after 9 months of surgical excision. Additional therapy was not performed.

The excised mass was fixed in $10 \%$ neutral buffered formalin, embedded in paraffin wax, cut into $4 \mu \mathrm{m}$ sections, and stained with hematoxylin and eosin (HE), periodic acidSchiff (PAS), alcian blue, and oil red O stains. Serial sections were subjected to immunohistochemical (IHC) staining using a labeled streptavidin-biotin peroxidase technique with mouse monoclonal antibodies against low molecular weight cytokeratin (CK; clone CAM5.2, prediluted, BD Biosciences, Franklin Lakes, NJ, USA), CK8 (clone Ks 8.7, 1:50, Progen Biotechnik GmbH, Heidelberg, Germany), CK14 (clone LC002, 1:50, BioGenex Laboratories Inc., San Ramon, CA, USA), $\alpha$-smooth muscle actin ( $\alpha$ SMA; clone 1A4, 1:400, 
DAKO, Glostrup, Denmark), CK19 (clone 170.2.14, 1:100, Boehringer Mannheim, Germany), and p63 (clone 4A4, 1:400, NeoMarkers Inc., Fremont, CA, USA). All tissue sections were pretreated with citrate buffer ( $\mathrm{pH}$ 6.0) and incubated at $121^{\circ} \mathrm{C}$ for $15 \mathrm{~min}$. The reaction to each antigen was visualized by the addition of $3,3^{\prime}$-diaminobenzidine tetrahydrochloride chromogen and counterstained with hematoxylin.

Histologically, the mass was well demarcated and encapsulated. It consisted of various nodules and proliferating nests mainly composed of bilayered ductal structures with an inner layer of cuboidal to columnar luminal epithelial tumor cells and an outer layer of basaloid tumor cells separated by a thin fibrous stroma (Figure 1). The inner layer of luminal epithelial cells had clear cytoplasm and small hyperchromatic nuclei. The outer layer of basaloid tumor cells had scant eosinophilic cytoplasm and slightly larger euchromatic nuclei. Mitotic activity was moderate. Within the tumor, there were a few nests of large foamy cells similar to the sebaceous cells surrounded by basaloid cells (Figure 2). The nuclei of these cells were centrally located with finely vacuolated cytoplasm and were negative for PAS and alcian blue staining but positive for lipids by oil red $\mathrm{O}$ staining (Figure 2 inset). No squamous differentiation or keratinization was observed within the tumor. Furthermore, no necrosis, invasion, or emboli of the tumor cells was observed.

As shown in Table 1, immunohistochemical staining revealed that the luminal epithelial tumor cells were positive for CK19 (Figure 3) and CAM5.2 but not for CK14, $\alpha$ SMA, and $\mathrm{p} 63$. In contrast, basaloid tumor cells were positive for CK14 (Figure 4), p63 (Figure 5), and $\alpha$ SMA but not for CK19 and CAM5.2. CK8 expression was observed in both luminal epithelial and basaloid tumor cells (Figure 6). The tumor cells showing sebaceous differentiation were positive for CK14 but not for the other markers.

\section{Discussion}

On the basis of the histological and immunohistochemical findings, the tumor was diagnosed as an apocrine sweat gland ductal adenoma with sebaceous differentiation. According to the World Health Organization classification of epithelial and melanocytic tumors of the skin of domestic animals, benign tumors of the apocrine sweat gland are classified as apocrine adenomas, complex and mixed apocrine adenomas, or apocrine ductal adenomas [2]. In dogs, sebaceous differentiation has been described in four cases of mammary gland tumors: two complex adenomas $[3,4]$ and two carcinomas $[5,6]$ and a case of salivary gland tumor [7], whereas one has not been previously described in apocrine sweat glands. The present report describes a case of apocrine sweat gland ductal adenoma with sebaceous differentiation occurring in the buccal skin of Border Collie.

CK19 and CAM5.2 are useful markers of luminal cell markers, while CK14, p63, and $\alpha$ SMA are markers of basal/ myoepithelial cells in dogs [1, 8-11]. CK8 expression has been observed in both luminal and basaloid cells in canine apocrine gland tumors [12]. In contrast, CK14 was expressed

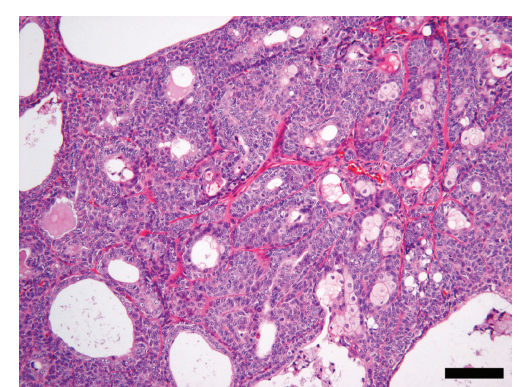

Figure 1: Histopathological appearance of the buccal mass. The mass is composed of the ductal structures lined by the bilayered luminal epithelial and basaloid tumor cells. Hematoxylin and eosin (HE). $\mathrm{Bar}=100 \mu \mathrm{m}$.

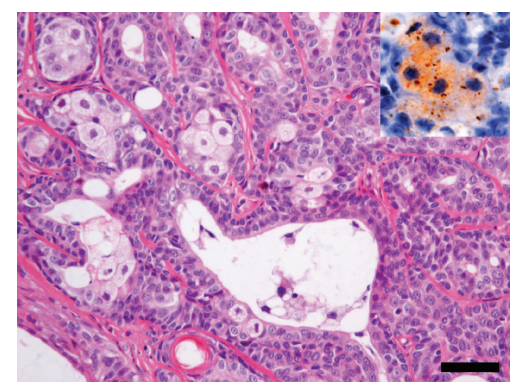

FIGURE 2: Sebaceous differentiation observed within the apocrine ductal adenoma. Sebaceous cells are characterized by abundant, clear, and vacuolated cytoplasm and a centrally located nucleus surrounded by basaloid cells in the apocrine ductal adenoma. HE. $\mathrm{Bar}=50 \mu \mathrm{m}$. Inset: a frozen section stained with oil red $\mathrm{O}$ revealing the lipid droplets within the cytoplasm of sebaceous cells.

TABLE 1: Summary of immunohistochemical findings.

\begin{tabular}{lcccccc}
\hline Tumor cell type & CAM5.2 & CK8 & CK14 & CK19 & p63 & $\alpha$ SMA \\
\hline Luminal cells & + & + & - & + & - & - \\
Basaloid cells & - & + & + & - & + & + \\
Sebaceous-like cells & - & - & + & - & - & - \\
\hline
\end{tabular}

in the normal sebaceous gland and myoepithelial cells of apocrine and mammary glands $[3,4,10]$. $\alpha$ SMA expression was observed in the myoepithelial cells but not in the basaloid cells in apocrine gland tumors [10]. In canine apocrine carcinoma, $\mathrm{p}^{+}{ }^{+} \mathrm{SMA}^{+}, \mathrm{p} 3^{+} \mathrm{SMA}^{-}$, and $\mathrm{CK}^{+}{ }^{+} 63^{-}$cells were identified in myoepithelial, basaloid, and luminal cells, respectively [13]. Additionally, in concordance with previous studies, this tumor primarily consisted of two tumor cell types, luminal cells and basaloid cells, with sebaceous differentiation.

This tumor appeared to be differentiated from a sebaceous adenoma and trichoblastoma of the skin. The tumor characteristics in the present case included cellular proliferation with bilayered ductal structures with sebaceous differentiation, which is not a feature of a sebaceous tumor or trichoblastoma. Canine mammary gland tumors are often observed in squamous differentiation $[3,4]$. Some canine apocrine sweat gland ductal adenomas have foci of squamous differentiation 


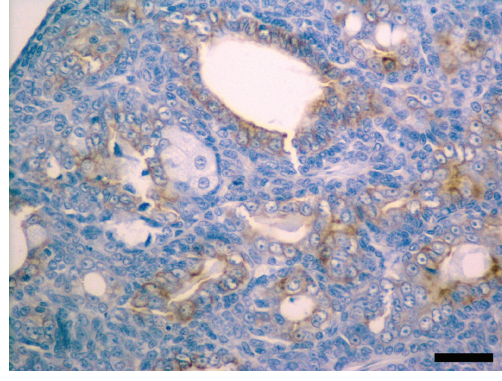

FIGURE 3: Luminal tumor cells are positive for CK19. Immunohistochemistry for CK19 with hematoxylin counterstain. Bar $=50 \mu \mathrm{m}$.

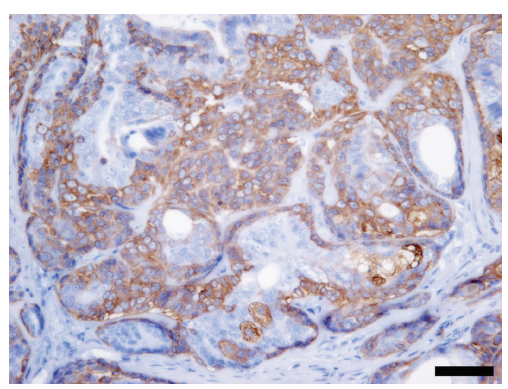

FIGURE 4: Basaloid tumor cells and cells showing sebaceous differentiation are positive for CK14. Immunohistochemistry for CK14 with hematoxylin counterstain. Bar $=50 \mu \mathrm{m}$.

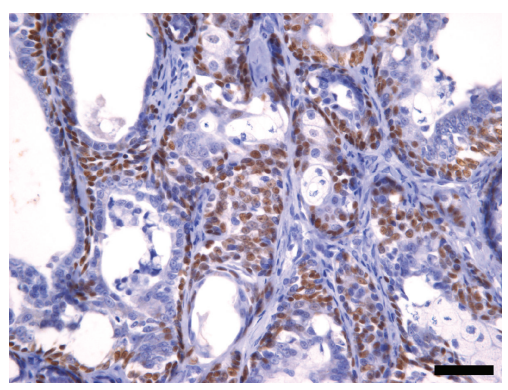

FIGURE 5: Basaloid tumor cells are positive for p63. Immunohistochemistry for p63 with hematoxylin counterstain. Bar $=50 \mu \mathrm{m}$.

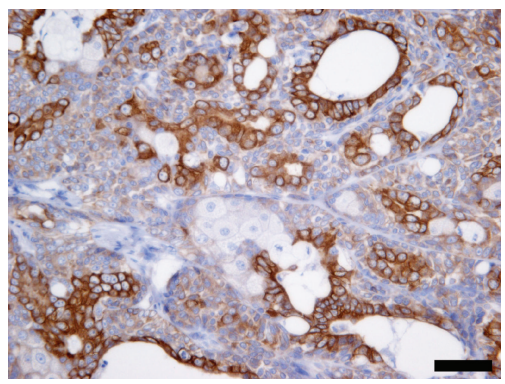

FIGURE 6: Both luminal and basaloid tumor cells are positive for CK8. Immunohistochemistry for CK8 with hematoxylin counterstain. Bar $=50 \mu \mathrm{m}$. with small keratin deposits in the infundibular portion of the apocrine duct [2]. However, squamous differentiation was not observed in this case.

The origin of the sebaceous component in this tumor was unclear. However, previous studies suggested that tumor basaloid cells can differentiate into sebaceous epithelial cells and that cutaneous stem cells might give rise to sebocytes in canine mammary tumors $[5,14,15]$. Therefore, we propose that the sebaceous differentiation in this tumor may have been derived from basaloid cells or local pluripotent stem cells, similar to canine mammary gland tumors.

\section{Conflict of Interests}

The authors declare that there is no conflict of interests.

\section{Acknowledgments}

The authors would like to thank Dr. Hidemi Kitagawa for providing the follow-up information and the tumor specimen for this study and Drs. Yoko Matsuda, Toshiyuki Ishiwata, and Zenya Naito from Departments of Pathology and Integrative Oncological Pathology, Nippon Medical School, for their helpful discussions.

\section{References}

[1] M. H. Goldschmidt and F. S. Shofer, "Apocrine gland tumors," in Skin Tumors of the Dog and Cat, M. H. Goldschmidt and F. S. Shofer, Eds., pp. 85-89, Pergamon Press, Oxford, UK, 1992.

[2] M. H. Goldschmidt, R. W. Dunstan, A. A. Standnard et al., "Histological classification of epithelial and melanocytic tumors of the skin of domestic animals," in World Health Organization International Histological Classification of Tumors of Domestic Animals, F. Y. Schulman, Ed., pp. 21-32, Armed Forces Institute of Pathology (AFIP), Washington, DC, USA, 1998.

[3] K. Yasuno, Y. Takagi, R. Kobayashi et al., "Mammary adenoma with sebaceous differentiation in a dog," Journal of Veterinary Diagnostic Investigation, vol. 23, no. 4, pp. 832-835, 2011.

[4] A. G. Kurilj, M. Hohšteter, A. Beck, B. Artuković, I.-C. Šoštarić-Zuckermann, and Ž. Grabarević, "Complex mammary adenoma with sebaceous differentiation in a dog," Journal of Comparative Pathology, vol. 146, no. 2-3, pp. 165-167, 2012.

[5] S. C. Chang, J. W. Liao, M. L. Wong, Y. S. Lai, and C. I. Liu, "Mammary carcinoma with sebaceous differentiation in a dog," Veterinary Pathology, vol. 44, no. 4, pp. 525-527, 2007.

[6] F. Grandi, M. M. Colodel, R. M. Rocha, and J. L. Sequeira, "Sebaceous metaplasia in a canine mammary gland noninfiltrative carcinoma with myoepithelial component," Journal of Veterinary Diagnostic Investigation, vol. 23, no. 6, pp. 12301233, 2011.

[7] O. A. Smrkovski, A. K. LeBlanc, S. H. Smith, C. J. LeBlanc, W. H. Adams, and K. M. Tobias, "Carcinoma ex pleomorphic adenoma with sebaceous differentiation in the mandibular salivary gland of a dog," Veterinary Pathology, vol. 43, no. 3, pp. 374-377, 2006.

[8] A. Gama, A. Alves, F. Gartner, and F. Schmitt, "p63: a novel myoepithelial cell marker in canine mammary tissues," Veterinary Pathology, vol. 40, no. 4, pp. 412-420, 2003. 
[9] A. L. Saraiva, F. Gärtner, and M. A. Pires, "Expression of p63 normal canine skin and primary cutaneous glandular carcinomas," Veterinary Journal, vol. 177, no. 1, pp. 136-140, 2008.

[10] K. Yasuno, S. Nishiyama, F. Suetsugu, K. Ogihara, H. Madarame, and K. Shirota, "Cutaneous clear cell adnexal carcinoma in a dog: special reference to cytokeratin expression," Journal of Veterinary Medical Science, vol. 71, no. 11, pp. 1513-1517, 2009.

[11] A. Gama, A. Alves, and F. Schmitt, "Expression and prognostic significance of CK19 in canine malignant mammary tumours," Veterinary Journal, vol. 184, no. 1, pp. 45-51, 2010.

[12] K. Kato, K. Uchida, K. Nibe, and S. Tateyama, "Immunohistochemical studies on cytokeratin 8 and 18 expressions in canine cutaneous adnexus and their tumors," Journal of Veterinary Medical Science, vol. 69, no. 3, pp. 233-239, 2007.

[13] A. Shiraki, Y. Hojo, T. Tsuchiya et al., "Complex apocrine carcinoma with dominant myoepithelial proliferation in a dog," Journal of Veterinary Medical Sciences, vol. 74, no. 6, pp. 801804, 2012.

[14] F. A. Tavassoli and H. J. Norris, "Mammary adenoid cystic carcinoma with sebaceous differentiation. A morphologic study of the cell types," Archives of Pathology and Laboratory Medicine, vol. 110, no. 11, pp. 1045-1053, 1986.

[15] Y. F. Jiao, S. Nakamura, T. Oikawa, T. Sugai, and N. Uesugi, "Sebaceous gland metaplasia in intraductal papilloma of the breast," Virchows Archiv, vol. 438, no. 5, pp. 505-508, 2001. 

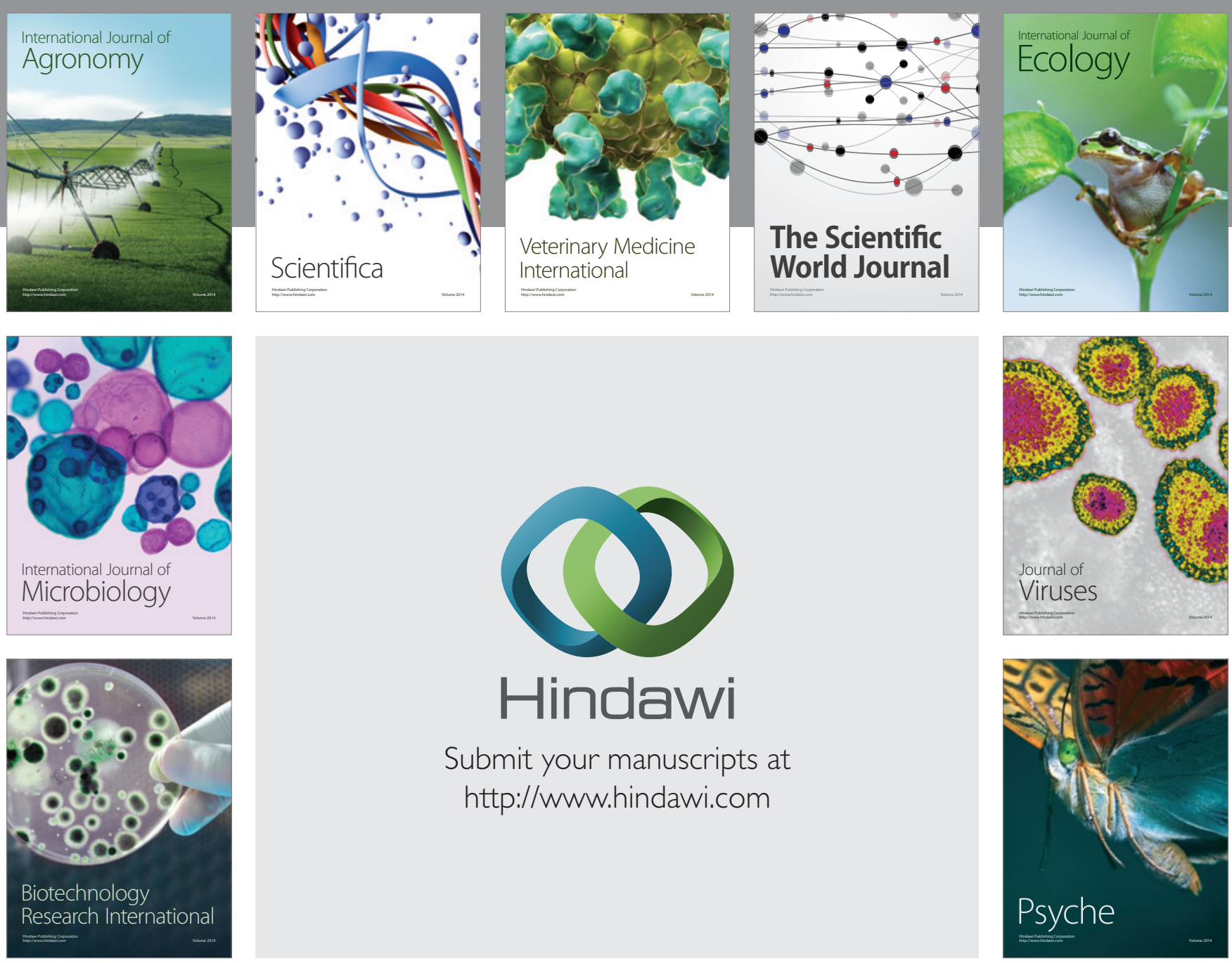

Submit your manuscripts at

http://www.hindawi.com
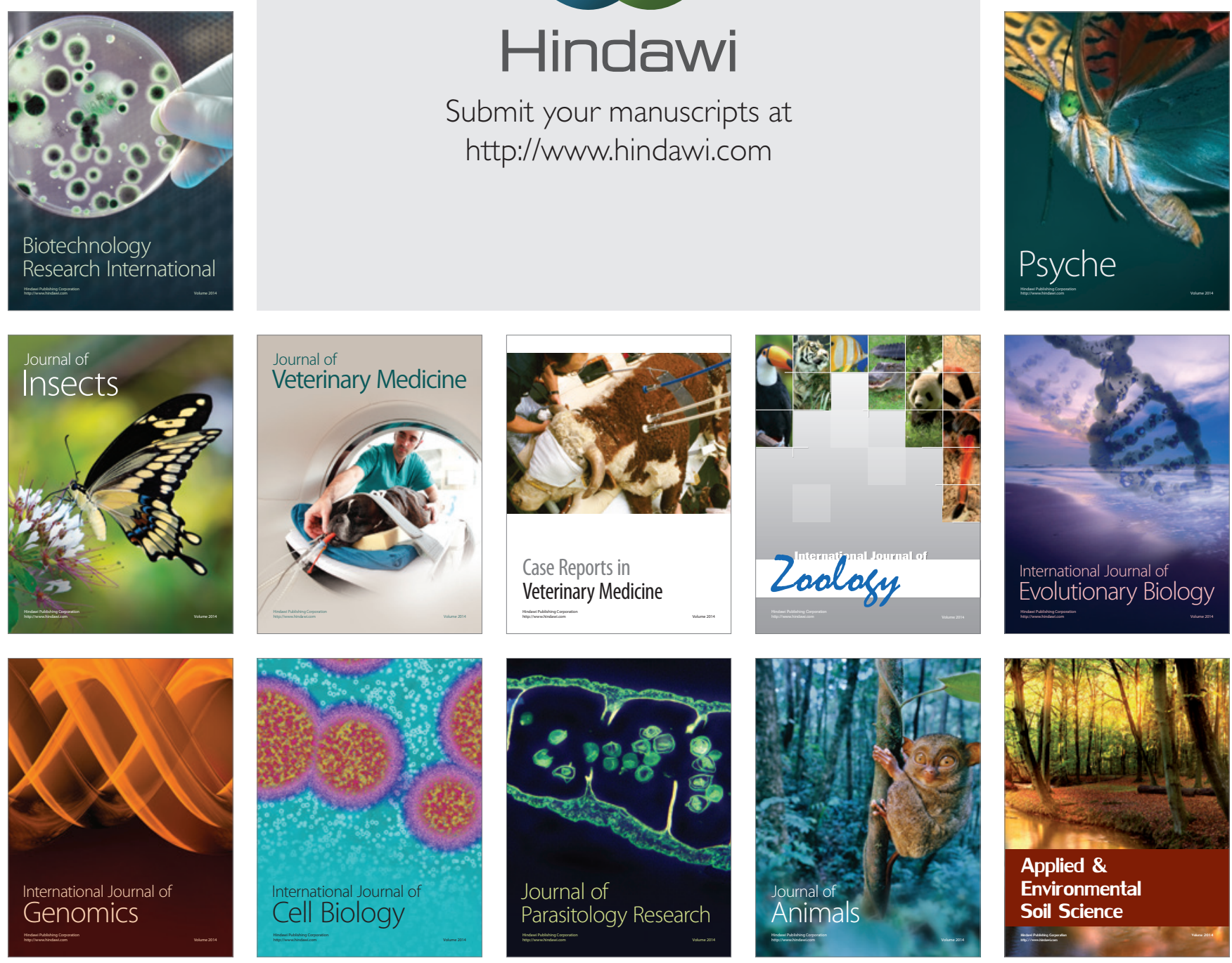